\title{
Adaptation Information and analytical system adaptation in the contour of the corporate system of the university
}

\author{
Natalya Kolyeva ${ }^{1}$, Oxana Kopnova ${ }^{2}$, and Anna Shaporeva ${ }^{2}$ \\ ${ }^{1}$ Ural State University of Economics, Yekaterinburg \\ ${ }^{2}$ Department of Mathematics and Informatics, North Kazakhstan State University. M Kozybaeva, \\ Petropavlovsk, Kazakhstan
}

\begin{abstract}
The article discusses the advantages of embedding an information and analytical system in the contour of the corporate system of the university. The purpose of the development and implementation of the information and analytical system is formulated. Its features are determined, as well as the rationale for choosing the implementation environment. The place of the information and analytical system in the contour of the corporate system of the university is indicated. The model of the data structure of the information and analytical system in the contour of the corporate information system of the university is presented. Typical problems in the organization's infrastructure are identified and solutions for optimizing the work are proposed. A reasoning model for analyzing corporate information system data is constructed. The levels of access to the analytical system are defined. This information is useful for both managers of educational institutions and employees of services involved in processing information about the organization and reporting for making strategic decisions.
\end{abstract}

\section{Introduction}

The purpose of this article is to describe the methods of data analysis of corporate information systems using an information and analytical system, as well as to identify hidden dependencies and patterns to improve the quality of decisions made on the example of interactive analytical reports.

Today, the requirements for university management are increasing, which leads to the inclusion of information and analytical systems in the management circuit. The information and analytical system in the management of the scientific and educational activities of the university should not only provide the administrative management of the university with information about the current and future state, but also identify problem areas of the functioning of the university's scientific and educational activities, develop corrective actions to strengthen work in this direction.

The introduction of new educational and information technologies into the corporate information system of the university and the formation of a unified educational space are currently the dominant trends that determine the development of the education system. Information and analytical systems should be developed taking into account the need to meet 
all the requirements of the university's development strategy as well as all the socially significant areas of the university's activities. The main task that the head of an educational organization faces is the introduction of new information technologies into the education system, which would allow them to be used both for teaching and for managing the educational process. To achieve this goal, it is often necessary to develop an information and analytical system that allows you to accumulate data from disparate information systems of the organization.

Interpretation of the results of the analysis will allow the head of the organization to control and make predictive decisions concerning both the internal and external situation. Since university management, improving the quality of the scientific and educational process is a complex task that requires a systematic and timely analysis of comprehensive and reliable information about the state and problems of the university's activities, which is possible only as a result of the introduction of modern information technologies in the process of university management and their constant improvement.

The approaches proposed in the article can be used not only in educational organizations since the effect of using information and analytical system is due to a number of factors:

- reducing the time required to generate reporting information by providing interactive dashboards for end users to select the necessary information;

- ability to receive operational data while outside the organization;

- ability to evaluate the advantage of the decision based on the information provided;

- optimization of management decision making by providing complete and reliable information.

\section{Place of the information and analytical system within the information space of the university}

There are several approaches to defining Business Intelligence (BI). By one definition, Business Intelligence refers to the collection of business data to find information primarily through questions, reporting, and online analytical processes. Business analytics uses statistical and quantitative tools to understand the current situation and to make predictions.

In an alternative definition, Thomas Davenport [1], a professor of information technology and management at Babson College, argues that BI should be divided into the following stages: information retrieval; online analytical processing (OLAP); tools for warning about deviations from expected indicators; business analytics; business reporting. In this definition, business analytics is a subset of BI and deals with statistics, forecasting, and optimization. So BI is not just about reporting.

Also in the post-soviet space, the concept of an information and analytical system (IAS) was fixed [2-3, 4]. Its functions include analytical processing of data stored in the database of the corporate information system. IAS usually have a certain set of rules designed to solve problems that arise in the field of information processing, as well as modular functionality for displaying data.

Despite the great differences in these definitions, they have one common idea: a system built on the principles of BI allows the head of a university, enterprise or organization to make informed decisions and, as a result, it can be a source of competitive advantages. The main task of such systems is to improve the timeliness and quality of information.

IT managers and business leaders are increasingly claiming that the most important asset of a company is information. Realizing this, since the end of the nineties of the 20th century, the development of a metadata repository has begun; these are structures and technologies for collecting information. There are a number of patent solutions related to the storage of metadata [5-9]. Despite this, in the scientific world, there are still disputes over the presentation and storage of metadata [10-11]. 
Let's list the main reasons why the use of a BI system is effective: structuring and combining business processes into a single system; improving the quality of information; transition to the level of strategic planning and achievement of highly effective decisions.

Management decision-making is based on a comprehensive analysis of reliable and accessible information. Such information can be stored both in structured databases and in the form of unstructured data. An example of unstructured information can be various reports that are generated by employees of an organization. For analytical analysis, data on the number of unstructured sources are usually used.

The analytical activity of the university and organizations has a number of similarities and differences, we list the general ones: analysis of economic activity; technical and economic analysis; legal analysis; audit analysis.

Distinctive characteristics of the activities of educational institutions are analysis of educational activities; analysis of educational and methodological activities; analysis of scientific and innovative activities; analysis of educational and social activities.

System integration market experts [12] argue that there is no foreseen for the widespread transition of companies to cloud BI platforms. Despite the fact that it is easier to use external solutions than to deploy one's own IT infrastructure. The main reason is that it is too risky to place complete information containing detailed data on the organization's activities in cloud data storages. They believe that hosting data on cloud platforms is relevant for small and medium-sized companies that process publicly available information. The reasons for such pessimistic forecasts, according to S. Gromov (CEO of BI Consult), are as follows [12]:

1. Few good solutions;

2. High security requirements for the information provided;

3. Automatic loading of data to cloud storage is poorly thought out.

Thus, we can conclude that the differences between the use of BI systems for business and for a university are significant. That is why the choice of the optimal implementation environment is an important step in creating a BI system for a university. The information infrastructure of a university is a set of solutions of its own and local developments and forms an information space [13]. Its own developments include information systems for the automation of educational activities, scientific work of students and faculty teachers, the use of distance learning technologies, as well as indicators of the implementation of the indicative plan. Local developments are third-party solutions and perform the functions of automating financial and economic activities, electronic document management systems, using control software to administer key resources and services, educational software and software solutions for managing IT service resources.

Often, the head is faced with the problem of obtaining relevant and reliable data stored in disparate local systems of the information space of the university. The heads of structural divisions face the same problem during the period of writing reports and various inspections aimed at monitoring education. The preparation of analytical reports takes a lot of time and additional workload for training and support staff. Therefore, there is a need to create information and analytical systems that allow consolidating the data of information systems of the university for the implementation of analytical management functions, revealing hidden patterns and making balanced management decisions.

Figure 1 schematically shows the place of the information and analytical system (IAS) in the information space of the university. 


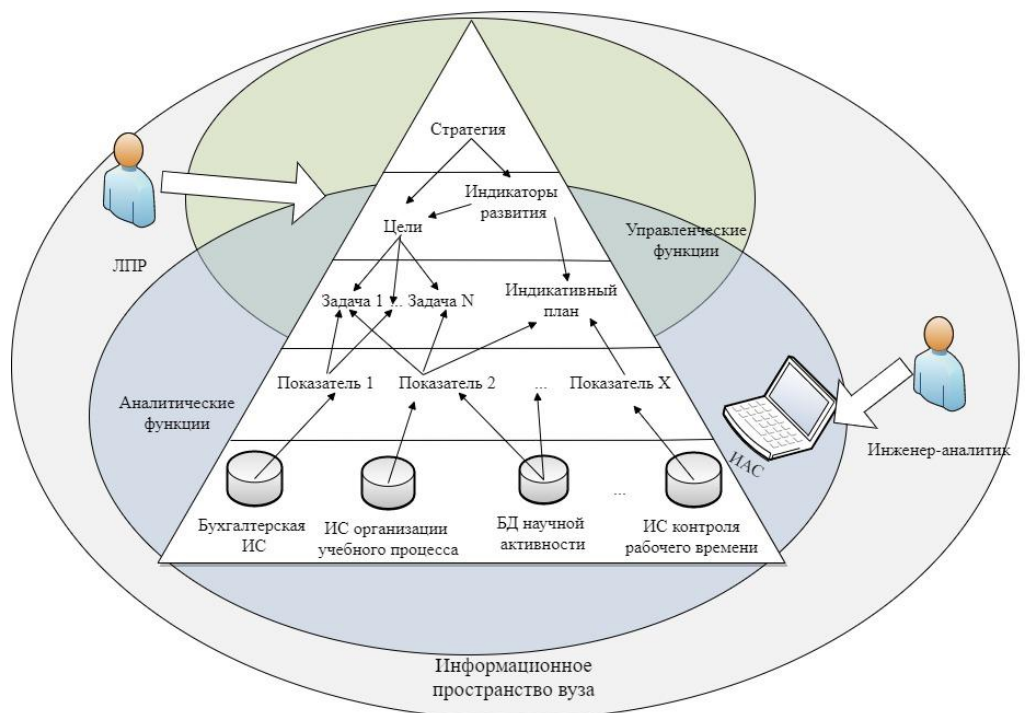

Fig. 1. The place of the IAS in the information space of the university.

Where: ЛПР (лицо, принимающее решение)-Decision maker; Аналитические функции- Analytical functions; Управленческие функции-Management functions; Стратегия-Strategy; Индикаторы развития-Development indicators; Цели-Goals; Задача 1-Task 1; Задача N-Task N; Индикативный план- Indicative plan; Показатель 1-Indicator 1; Показатель 2-Indicator 2; Показатель X-Indicator $\mathrm{X}$; Бухгалтерская ИС - Accounting Information System; ИС организации учебного процессаInformation System of the Educational Process - Organization ; БД научной деятельности - Scientific Activity Databases; ИС контроля рабочего времени Time - Management; Information System; Инженер-аналитик - Analytical Engineer; Информационное пространство вуза - University Information Space.

The information and analytical system (IAS) is a modern highly effective tool to support the adoption of strategic, tactical and operational management decisions based on the visual and prompt provision of the entire necessary set of data to users responsible for analyzing the state of affairs and making management decisions.

The complex of information and analytical systems affects the entire management vertical of the university: corporate reporting, financial and economic planning and strategic planning. The main purpose of the IAS is dynamic presentation and multidimensional analysis of historical and current data, trend analysis, modeling and forecasting the results of various management decisions.

The main features of the information and analytical system [9]: it should help improve the quality of management decisions through the application of rules, procedures and technologies that allow to structure and automate information management processes; should analyze data obtained from various sources (both internal and external); it should be a separate software product, functioning separately from the child systems, but have two-way interaction with them.

To implement IAS, methods and models were used, such as: programming technologies, design of information systems, database theory, statistics, artificial intelligence, machine learning, data mining, economic and mathematical modeling.

An information-analytical system is a platform in which databases (MS SQL, MySQL, etc.) of disparate information systems of an organization's information infrastructure and transactional data sources are integrated. This data integration accumulates at the cloud storage layer. The cloud architecture of the platform allows you to connect various intelligent data mining services, such as Microsoft Azure Learning, Analysis Services and Google Analytics, for the purpose of building [12]. Together, using a systematic approach, as well as 
applying methods and models of economic and mathematical modeling and data mining, it is possible to build visualization services and predictive analytics. With the Power BI service, you can securely publish reports to your organization and set up automatic data refresh to keep all users up to date.

\section{Conclusions}

Information plays an important role in the development of an organization as a commodity and as a resource. Without exception, all processes depend on information when making management decisions and developing a strategy [14-16]. From the technological point of view of university management, the information space consists of information resources, information interaction tools and information infrastructure. However, this approach cannot fully describe the information interaction since it does not reflect the level of satisfaction of the needs of the end users of the system. The approach considered in this study suggests orienting the information space of the university to the end user by creating a BI system for the university that accumulates data from the corporate information system and transforms it into knowledge using data processing algorithms.

The users of the information space of the university are the rector, vice-rectors, and heads of structural divisions, deans and heads of the department, faculty, and students of faculties, applicants, parents and members of the public. Each of them has its own role and influences on the development of the information space as a whole.

Competent organization of interaction within the information space of the university will simplify the work and organize interaction at the following levels of data management [1720]:

- Operational - automation of routine operations by creating regulated analytical reports targeted at end users of various categories;

- Tactical - providing control and management of the educational process, pedagogical and scientific activities, as well as educational indicators;

- Strategic - a comprehensive solution to the problems of increasing the efficiency of educational processes of the university, providing management with data analysis tools, as well as increasing management efficiency.

The BI system within the information space of the university is designed to help in identifying non-obvious patterns and making management decisions based on the knowledge gained. It is a superstructure over the corporate information system of the university and solves the following tasks:

1. Structuring and integration of information and financial processes into a single system;

2. Improving the quality of information by providing tools for interactive analysis of information and generating custom reports;

3. Possibility to assess and develop each of the areas of the university's activities;

4. Providing data for strategic planning.

Based on the foregoing, we can conclude that information is the main production resource for making management decisions. Successful management is impossible without the interaction of the decision maker with the data, which, in turn, are often stored in disparate sources of the information space of the university. For quick access, analysis of information and further decision-making, it is necessary that the information be pre-processed, structured and transformed. The function of organizing analytical reporting from disparate data of the corporate information system is taken over by the BI system for the university. The tasks of the analytical engineer include transforming the data of the corporate information system and data from external sources into useful information and knowledge used in management by identifying indicators and generating interactive reports. Interactive reports can contain data from one system, or from several, depending on the requirements for the data for analysis. 


\section{References}

1. T. H. Davenport, Analytics at work, 288 (2009)

2. Information and analytical system and its creation, Businessman.ru, https://businessman.ru/

3. B. Franks, Revolution in Analytics: How to Improve Your Business with Operational Analytics in the BigData Era, 316

4. T. V. Alekseeva, Yu. V. Ameridi, M. G. Luzhetskiy, Information and analytical systems (2005) http://www.e-biblio.ru/

5. J. F. Clinton, J. Hallman, Leslie W. Vaughn, Method and apparatus for using a static metadata object to reduce database accesses, BMC Software Inc Network Associates Inc Patent US6393424B1, 29-12 (1999)

6. H. P. Teck, K. T. Poh, W.-J. Sng and S. Stadel, Metadata database management system and method therefor, Reuters Ltd Patent US7613728B2 0204 (2002)

7. S. B. Nori, C. Pae, B. Thiagarajan, Method (s) for updating database object metadata, Oracle International Corp. Patent US7809763B2, 1510 (2004)

8. M. A. Greenstein, G. Grunin, M. N. Schwenger, S. Pandikumar, Enabling collaborative development of a database application across multiple database management systems, International Business Machines Corp Patent US20180107690A1, 1501 (2014)

9. T. Hanusiak, W. Konrad, O. Jaroslaw and G. Szczepanik, Mapping database structure to software, International Business Machines Corp Patent US20180018365A1, 1807 (2016)

10. Oksana L. Zavalina, Priya Kizhakkethil, Daniel Gelaw Alemneh, Mark E. Phillips, Hannah Tarver, Journal of Information \& Knowledge Management, 14(1), 1-16 (2015)

11. P. Pinoli, S. Ceri, D. Martinenghi, L. Nanni, Information Systems, 81, 1-20 (2019)

12. Integrators about the trends of the BI-market, https://korusconsulting.ru/

13. G. Mutanov, Z. Mamykova, O. Kopnova, The 1st International Conference on Business Technology for a Sustainable Environmental System (BTSES-2020), 159, (2020)

14. Ualsher A. Tukeyev, Aizhan A. Altaibek, Models and Algoritm of Designing if databases with the High Degree, Varia Informatica, PIPS Polish Information Processing Society, 65-91 (2011)

15. K. Schwab, The Fourth Industrial Revolution, 208 (2017)

16. A. Yurchenko, Information technology, Theoretical and applied scientific and technical journal, 24(4), 219-231 (2018)

17. A. Terekhov, Gartner bi magic quadrant 2018: Business intelligence market overview (2018) http://blog.atkcg.ru/

18. H. P. Levy, Why and How to Value Your Information as an Asset, Smarter With Garthner (2015) https://www.gartner.com/

19. S. Moore, Take Your Analytics Maturity to the Next Level, Smarter With Garthner, (2018) https://www.gartner.com/

20. B. M. C. Hatem, Metadata application programming interface for ad hoc database queries, SAP SE Patent US20180096032A1, 3009 (2016) 